\title{
Clinical Profile and Outcome of Ventilated Children in a Pediatric Intensive Care Unit (PICU): A Study in Dhaka Shishu (Children) Hospital, Dhaka, Bangladesh
}

\author{
Md. Shafiul Hoque ${ }^{1 *}$, Probir Kumar Sarkar ${ }^{2}$, A.S.M. Nawshad Uddin Ahmed ${ }^{3}$
}

${ }^{1}$ Associate Professor of Paediatrics, MD, Bangladesh Institute of Child Health, Dhaka Shishu (Children) Hospital, Dhaka 1207, Bangladesh ${ }^{2}$ Associate Professor of Paediatrics, FCPS, Bangladesh Institute of Child Health, Dhaka Shishu (Children) Hospital, Dhaka 1207, Bangladesh ${ }^{3}$ Professor of Paediatrics, FCPS, Bangladesh Institute of Child Health, Dhaka Shishu (Children) Hospital, Dhaka 1207, Bangladesh

*Corresponding author: Md. Shafiul Hoque

Background: Mechanical Ventilation (MV) has become frequently used life-supportive management in Pediatric Intensive Care Units (PICU). But very little data is available from developing countries regarding the outcome analysis coupled with demographic status and clinical details which is a challenge for the modern day intensivists. Objective: To determine the characteristics and outcome of ventilated patients in the pediatrics medical intensive care unit in Dhaka Shishu (Children) Hospital, Dhaka, Bangladesh. Methods: A prospective descriptive study was conducted on ventilated children admitted to PICU from January to December 2019. The factors studied included demographic and clinical profile, length of stay on ventilator, indications for ventilation and the final outcome. Results: A total of 144 (23\%) cases admitted in PICU were ventilated over the period of one year. Male to female ratio was 1.36 : 1. Neurological $(27.8 \%)$ and respiratory $(25.6 \%)$ causes were found to be the commonest indicators of ventilation in the study. The average ventilator stay was 2.4 days and hospital stay was 9.71 days. $51 \%$ of ventilated cases were infants and $81 \%$ of total deaths occurred under five years age group. $49.3 \%$ of ventilated cases were successfully discharged and neurological cases had a better outcome (64\%) among all the cases. Conclusion: This study provides an insight into the present status of PICU in Dhaka Shishu (Children) Hospital analyses the limitations and recommends the need to strengthen PICU to improve the quality care for the better survival of critically ill children.

Keywords: Indications, Mechanical Ventilation, Outcome, PICU, Ventilator stay.

Copyright $\odot 2020$ The Author(s): This is an open-access article distributed under the terms of the Creative Commons Attribution 4.0 International License (CC BY-NC 4.0) which permits unrestricted use, distribution, and reproduction in any medium for non-commercial use provided the original author and source are credited.

\section{INTRODUCTION}

With the advancement in intensive care facilities, there is a dramatic increase in survival of critically ill children. Previous studies have shown significant positive impact of Intensive Care Unit (ICU) physicians on the outcome in children and adults $[1,2]$. ICU is also one of the sites where medical errors are most likely to occur because of the complexity of the diseases and patients are vulnerable to experience adverse outcomes due to multiple interventions [3-6]. Hence, it is obligatory for the intensivists to scrutinize the events occurring in the PICU and outcome of mechanically ventilated children for improving the quality care of the critically ill children. Mechanical Ventilation (MV) is a life-supporting device, invasive technology of intensive care unit, to mimic the respiratory physiological function at the time of either impending or acute respiratory failure [7]. The percentage of children receiving mechanical ventilation in PICUs ranges from $17-64 \%$ in developed countries where PICUs is amature and established discipline of medicine [8-10]. But very little data is available from Asian countries regarding use of MV in PICUs [11-13]. Dhaka Shishu (Children) Hospital is one of the largest government pediatric hospitals in the country. Government supported tertiary level public hospital for children 650 beds. Sixteen have been allocated to the pediatrics medical intensive care unit (PICU). The PICU is staffed by two consultant pediatricians, one pediatric senior registrar and 6 residents. They are responsible for covering the PICU 24 hours a day and handling ventilators with back up support from biomedical engineer. Nurse to patient ratio is 1:4. Admission of a child to PICU is decided by the consultants. The number of patients ventilated in the PICU averages 20 to 25 per month. The PICU is supported by a lab which provides services round the clock. The current study is intended to provide a baseline status of outcome of ventilated cases and also 
serves to compare with other pediatric intensive care units. This study was intended to pursuit the gaps and the data provided can be utilized by the hospital authorities to develop strategies for improving PICU.

\section{MATERIALS AND METHODS}

A prospective descriptive clinical study was conducted in the PICU from January to December 2019 for a period of one year. We consecutively collected data from the case sheets of all ventilated paediatric patients till discharge or death. All the patients admitted for invasive ventilation during the study period were included in Dhaka Shishu (Children) Hospital, Dhaka, Bangladesh. In case of readmission, the patient was recorded only during the first admission. On recovery; patients were transferred to step down unit and later to pediatric wards. The following data were collected: age, gender; final diagnosis, co morbidities, treatment characteristics, length of stay on ventilator, length of stay in hospital and the outcome. Serial clinical and radiological assessments of patients included thorough physical examination, pulse oxymetry, arterial blood gas analysis and chest roentgenograms. Along with this the patients were investigated and treated for the primary diagnosis as per requirement of the case. Patients were followed till death or discharge from the hospital.

\section{STATISTICAL ANALYSIS}

Data was collected on a structured proforma designed and entered into Excel sheet. SPSS version 19 was used for statistical analysis. Descriptive statistics like mean, median, standard deviation and proportions were calculated for all the variables. To study the association of outcome with other variables chi square test was used. To compare mean value of ventilator stay in hours to outcome ANOVA with post hoc test of LSD (Least Significance Difference) was used. P value < 0.05 was considered significant.

\section{RESULTS}

During the period of the study, the total number of patients admitted to PICU was 627. Of which $144(23 \%)$ were ventilated. Out of 144 ventilated cases 83 were males and 61 were females. The male to female ratio was 1.36: 1 .

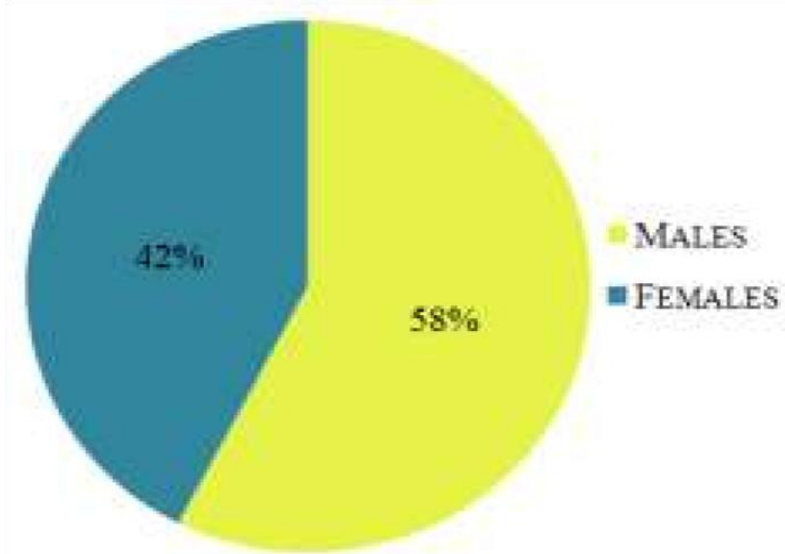

Fig-1: Sex distribution in the study

The mean age of children put on ventilator was found to be 3.05 years. The indications for ventilation are shown in Table-1. Neurological (27.8\%) and respiratory $(25.6 \%)$ causes were found to be the commonest indicators of ventilation in the study.

Table-1: Indications for ventilation

\begin{tabular}{|l|l|}
\hline Indications & Frequency $(\%)$ \\
\hline Cardiovascular & $24(17)$ \\
\hline MODS & $11(7.6)$ \\
\hline Neurological & $40(27.8)$ \\
\hline Respiratory & $37(25.6)$ \\
\hline Hepatic & $4(2.8)$ \\
\hline Infection & $14(9.7)$ \\
\hline Others* & $25(17.3)$ \\
\hline $\begin{array}{l}\text { * Include causes like snake bite, accidental poisonings, renal, haematological, metabolic, post - } \\
\text { operative surgical cases etc. }\end{array}$ \\
\hline
\end{tabular}

Table-2: Descriptive Statistics of Ventilator Stay \& Length of Stay in hospital

\begin{tabular}{|l|l|l|l|l|l|l|}
\hline Variable & N & Minimum & Maximum & Mean & Std. Deviation & Median \\
\hline Ventilator stay(hours) & 144 & 2 & 480 & 58.68 & 57.053 & 46.00 \\
\hline LOS(days) & 144 & 1 & 42 & 9.71 & 7.971 & 8.50 \\
\hline
\end{tabular}

Table-2 depicts the minimal, maximal and mean values of duration of stay on ventilator and length of stay in the hospital. The mean ventilator stay was 2.4 days and hospital stay was 9.71 days. The mean stay on ventilator for discharges was 76.3 hours and deaths were 43.05 hours. The mean for duration of stay was 13.82 days for discharges and 5.42 days for deaths. Out of 144 ventilated cases, 71(49.3\%) were discharged, $10(6.9 \%)$ cases Left against Medical Advice (LAMA) and $63(43.8 \%)$ cases died. 


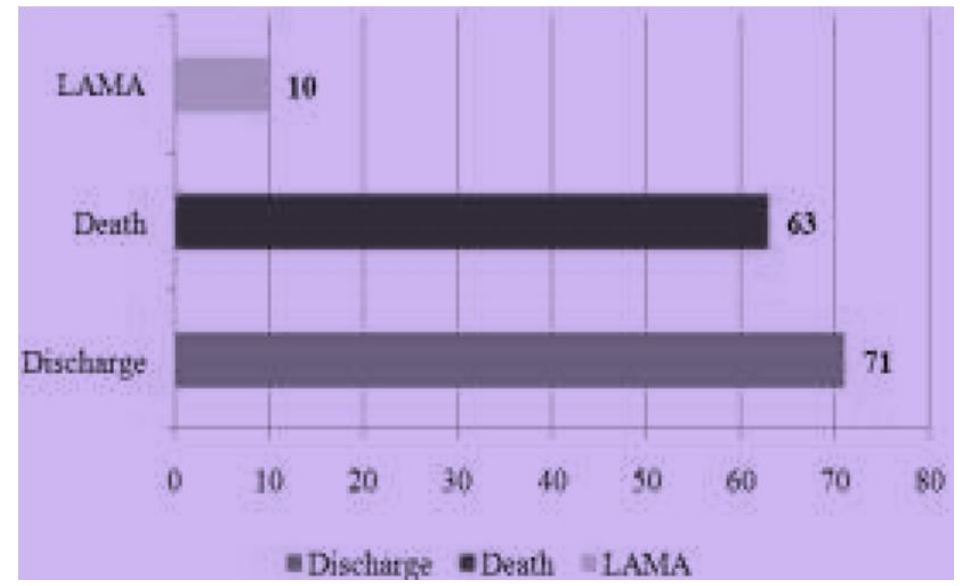

Fig-2: Outcome of the ventilated cases

In the present study, 73(51\%) ventilated cases were infants (1 month to 1 year), 41(28\%) were between 1 to 5 years and 30cases $(21 \%)$ belonged to age group of more than 5 years. Out of 73 infants, 38
$(52 \%)$ were discharged and $32(44 \%)$ died. Out of total 63 deaths, 51(81\%) occurred in children under five years.

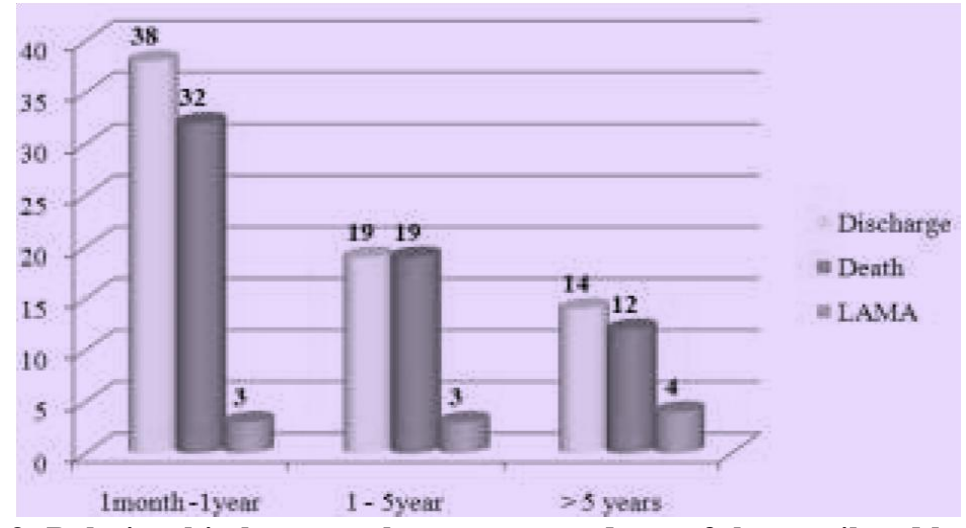

Fig-3: Relationship between the outcome and age of the ventilated babies

Mortality was significantly more for cases of Hepatic encephalopathy, DKA, MODS, Congenital heart diseases and Poisonings. Neurological cases had a better outcome $(64 \%)$ among all the cases. MODS on admission had $73 \%$ mortality. Table-3 depicts the relationship between diagnosis and outcome of the patients in the study.

Table-3: Relationship between diagnosis and outcome

\begin{tabular}{|l|l|l|l|l|}
\hline Diagnosis & Discharge & Death & LAMA & Total(n=144) \\
\hline Congenital Heart Disease & $5(27.8 \%)$ & $11(61.1 \%)$ & $2(11.1 \%)$ & $18(12.5 \%)$ \\
\hline MODS & $0(0 \%)$ & $8(73 \%)$ & $3(27 \%)$ & $11(7.6 \%)$ \\
\hline Meningitis & $6(60 \%)$ & $3(30 \%)$ & $1(10 \%)$ & $10(6.9 \%)$ \\
\hline TB Meningitis & $1(50 \%)$ & $1(50 \%)$ & $0(0 \%)$ & $2(1.4 \%)$ \\
\hline Pneumonia & $19(59.4 \%)$ & $12(37.5 \%)$ & $1(3.1 \%)$ & $32(22.2 \%)$ \\
\hline Hepatic Encephalopathy & $0(0 \%)$ & $4(100 \%)$ & $0(0 \%)$ & $4(2.8 \%)$ \\
\hline GBS & $6(75 \%)$ & $2(25 \%)$ & $0(0 \%)$ & $8(5.6 \%)$ \\
\hline I C Bleed & $4(66.7 \%)$ & $2(33.3 \%)$ & $0(0 \%)$ & $6(4.2 \%)$ \\
\hline VME & $4(57.1 \%)$ & $2(28.6 \%)$ & $1(14.3 \%)$ & $7(4.9 \%)$ \\
\hline Infectious & $6(46.2 \%)$ & $5(38.5 \%)$ & $2(15.4 \%)$ & $13(9 \%)$ \\
\hline Poisoning & $3(50 \%)$ & $3(50 \%)$ & $0(0 \%)$ & $6(4.2 \%)$ \\
\hline Snake bite & $2(66.7 \%)$ & $1(33.3 \%)$ & $0(0 \%)$ & $3(2.1 \%)$ \\
\hline Status Epilepticus & $3(75 \%)$ & $1(25 \%)$ & $0(0 \%)$ & $4(2.8 \%)$ \\
\hline Others* & $11(58 \%)$ & $8(42 \%)$ & $0(0 \%)$ & $19(13 \%)$ \\
\hline $\begin{array}{l}* \\
\text { metabolic, post - operative surgical cases etc. }\end{array}$ & & \\
\hline
\end{tabular}




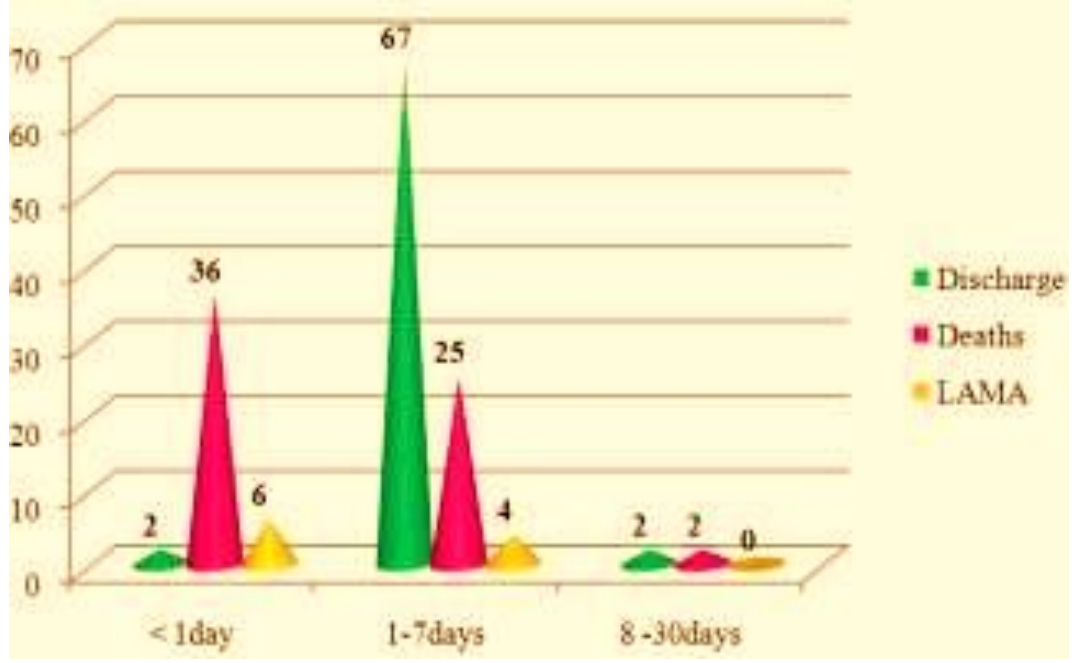

Fig-4: Relationship between ventilator stay and outcome

Out of 144 cases, $44(30 \%)$ cases were on ventilator for less than 24 hours, $96(67 \%)$ had ventilator stay between 1 to 7 days and only 4 (3\%) cases had a prolonged stay between 8 to 30 days. A mortality rate of $82 \%$ was found in cases put under ventilator for less than 24 hours which was statistically significant ( $\mathrm{p}<0.05$ ), while $70 \%$ of cases with a ventilator stay between 1 to 7 days were successfully discharged.

\section{DISCUSSION}

The percentage of admissions to PICU requiring Mechanical Ventilation (MV) in our study was $23 \%$ as found in study done in Pakistan by Shaukat $\mathrm{F}$ et al., [11]. But in the recent studies done by Vijayakumaryetal [12] in 2012, 52\% of children received MV in PICU of Sri Lanka and 50.7\% in study done by Mukhtar B et al., [13] in 2014 in Pakistan. Wolfler et al., reported that $34.6 \%$ of PICU admission in Italy required MV for $>24 \mathrm{hrs}$ [9]. Khemani et al., published that $30 \%$ of children in a cross-section of United States PICUs were mechanically ventilated [14]. The mean age of ventilated cases was 3 years and infants constituted the majority of cases; a similar phenomenon was appreciated in related studies [11-13]. Both neurological $(27.8 \%)$ and respiratory $(25.6 \%)$ causes were found to be the commonest indicators of ventilation in the study. In few studies [9, 13] acute neurological illness was found the major indications while several others reported [8, 12, 15-17] that respiratory failure due to respiratory illness was the most common indication of MV in PICUs. The most commonly used ventilatory mode was synchronized intermittent mandatory ventilation (SIMV) and several published reports also found that SIMV was commonly used as initial mode $[11,13,15,16]$. The duration of mechanical ventilation was 4-6 days in few published reports $[8,9,12]$. The average length of mechanical ventilation in our PICU was 2.4 days (range from 2 hours to 20days). The mortality rate of ventilated children was $43.8 \%$. Shaukat et al., and Kendiril et al., reported the survival rate were $63 \%$ and $58.3 \%$ from
Pakistan and Turkey respectively in the past [11, 15]. Vijayakumary et al., reported $27.6 \%$ mortality rate among mechanically ventilated patients [12]. In developed countries, the overall mortality rates in mechanically ventilated patients in PICUs were less than $2 \%$ [10]. This audit recognised several reasons for higher mortality in the ventilated children. Lack of adequate nursing staff in the PICU, with the nurse to patient ratio 1:4 when compared to the required $1: 1$ ratio in the PICU was found to be one of the significant contributing factors. Several reports have shown that full-time trained critical care specialists in both adult and paediatric ICUs improve the quality of care and are associated with lower mortality and morbidity rates [17]. Lack of trained pediatric intensivists, respiratory therapist services and regular trainings on MV were also identified as drawbacks in our set up. Selection of cases needs to be emphasized so that children must be put on ventilator before respiratory failure becomes clinically evident. In the present study, $82 \%$ mortality was noted in the ventilated cases with PICU stay less than or equal to 24 hours indicating very high mortality among patients who were put on mechanical ventilation for short periods of time, probably for terminal care. Patients were referred from faraway places and were admitted in poor status on admission. Hence delayed presentation with multiorgan dysfunction syndrome was also found to be important cause of higher mortality in the present study. Non-affordability of the exorbitant costs of PICU care in corporate hospitals even by middle class population has tremendously increased the case load over government tertiary care hospital (Dhaka Shishu (Children) Hospital, Dhaka, Bangladesh). It is therefore mandatory on part of government to establish PICU in every district and strengthen the existing PICUs to cater to the needs of larger population.

\section{CONCLUSION}

Pediatric Intensive Care is a distinct but still novice speciality in developing countries requiring dedicated experienced staff along with modern equipment and 24/7 availability of advanced laboratory 
services like ABGs and emergency medicines. Mechanical ventilation is one of the major supportive modalities used in critical care all over the world, but this treatment modality is being used in very limited number of sick children in few government tertiary care medical centres. Despite the limitations of a greater percentage of critically sick children arriving late, the overall survival is $49 \%$. To improve the outcome of MV children in PICUs, we need effective, organized and structured educational courses from basic concept to clinical application for all physicians and nurses involved in the care of critically ill children receiving mechanical ventilation. As we gain experience in the ventilation our complications rate and mortality related to mechanical ventilation would also decrease hopefully.

\section{REFERENCES}

1. Fiser DH, Tilford JM, Roberson PK. Difference in Pediatric ICU mortality risk over time. Crit Care Med, 1998; 26:1737-43.

2. Earle M. Outcomes of Pediatric Intensive Care at Six Centers in Mexico and Ecuador. Crit Care Med, 1997; 25: 1462-7.

3. Cullen DJ, Sweitzer BJ, Bates DW, Burdick E, Edmondson A, Leape LL. Preventable adverse drug events in hospitalized patients: a comparative study of intensive care and general care units. Crit Care Med, 1997; 25(8): 1289-97.

4. Andrews LB, Stocking C, Krizek T, Gottlieb L, Krizek C, Vargish T, Siegler M. An alternative strategy for studying adverse events in medical care. The Lancet. 1997 Feb 1;349(9048):309-13.

5. Giraud T, Dhainaut JF, Vaxelaire JF, Joseph T, Journois D, Bleichner G, Sollet JP, Chevret S, Monsallier JF. Iatrogenic complications in adult intensive care units: a prospective two-center study. Critical care medicine. 1993 Jan 1;21(1):4051.

6. Pronovost $\mathrm{P}, \mathrm{Wu} \mathrm{AW}$, Dorman $\mathrm{T}$, Morlock L. Building safety into ICU care. J Crit Care. Jun 2002; 17(2):78-85.

7. Mesiano G, Davis GM. Ventilatory strategies in the neonatal and paediatric intensive care units. Paediatr Respir Rev. 2008; 9(4):281- [9]. 288.
8. Farias JA, Frutos F, Esteban A, Flores JC, Retta A, Baltodano A, Alia I, Hatzis T, Olazarri F, Petros A, Johnson M. What is the daily practice of mechanical ventilation in pediatric intensive care units? A multicenter study. Intensive care medicine. 2004 May 1;30(5):918-25.

9. Wolfler A, Calderoni E, Ottonello G, Conti G, Baroncini S, Santuz P, Vitale P, Salvo I, SISPE Study Group. Daily practice of mechanical ventilation in Italian pediatric intensive care units: a prospective survey. Pediatric Critical Care Medicine Society of Critical Care Medicine. 2011 Mar 1;12(2):141-6.

10. Randolph AG, Meert KL, O'Neil ME, Hanson JH, Luckett PM, Arnold JH, Gedeit RG, Cox PN, Roberts JS, Venkataraman ST, Forbes PW. The feasibility of conducting clinical trials in infants and children with acute respiratory failure. American journal of respiratory and critical care medicine. 2003 May 15;167(10):1334-40.

11. Shaukat F mS, Jaffari SA, Malik A. Mechanical Ventilation in Children - A Challenge. Proceedings SZPGMI. 2000; 14(1):44-52.

12. Vijayakumary $\mathrm{T}$ dSJ, Sarathchandra J, Kumarendran B. Prospective study of ventilated patients in the pediatric medical intensive careunit of Lady Ridgeway Hospital. Sri Lanka J Child Health. 2012; 41(3):114-117.

13. Khemani RG, Markovitz BP, Curley MA. Characteristics of children intubated and mechanically ventilated in 16 PICUs. Chest. 2009; 136(3):765-771.

14. Kendirli T, Kavaz A, Yalaki Z, Ozturk Hismi B, Derelli E, Ince E. Mechanical ventilation in children. Turk J Pediatr. 2006; 48(4):323-327.

15. Harel Y, Niranjan V, Evans BJ. The current practice patterns of mechanical ventilation for respiratory failure in pediatric patients. Heart Lung. 1998; 27(4):238-244.

16. Khilnani P, Sarma D, Singh R. Demographic profile and outcome analysis of a tertiary paediatric intensive care unit. Indian Journal of Pediatrics, 2004; 71(7):587-91.

17. Goh AY, Abdel-Latif ME, Lum LC. Impact of 24hour critical care physician staffing on case-mix adjusted mortality in paediatric intensive care. Lancet, 2001; 357:445-6. 